\title{
The Skills Gap as Observed between IS Graduates and the Systems Development Industry - A South African Experience
}

\author{
Elsje Scott, Robert Alger, Simon Pequeno, Nicky Sessions \\ University of Cape Town, Cape Town, South Africa
}

\author{
escott@commerce.uct.ac.za rob@candor.com \\ spequeno@hitech-it-solutions.com nicky100@webmail.co.za
}

\begin{abstract}
This paper discusses the results of an investigation into the skills gap between Information Systems (IS) graduates at the University of Cape Town (UCT) and the South African Systems Development Industry. Three objectives were defined for this study. Firstly to measure the alignment between the level of skills possessed by students and the level of skills demanded by development companies. Secondly to identify and compare the most prominent specific skills that industry requires with the skills of students and thirdly to determine whether the students obtained the skills directly through UCT. The study revealed that there was alignment between the importance rating of companies and the skills of students in some areas, but not in others. Although correlation exists between the specific skills and technologies that industry requires and those which students possess, knowledge of certain technologies is lacking from the formal IS curriculum.
\end{abstract}

Keywords: Skills Gap, Systems Developments Skills

\section{Introduction}

The disparity between the quality and adequacy of skills possessed by IS (Information Systems) graduates and that required by the IT (Information Technology) industry, has come to be known as the skills gap. This issue is currently being discussed in numerous publications. The skills gap has considerable implications and consequences for IT companies and the industry as a whole. Therefore, it is important that universities measure the skills gap and align their curricula accordingly.

Our purpose was to determine how the level of systems development skills of IS students at UCT (The University of Cape Town) align with that of industry requirements within South Africa. Only the students eligible for graduation at the end of 2001 and only IT companies in South Africa were considered. This study was conducted endeavoring to assist in course curriculum design by the Department of IS at UCT or to be used in further research into this area. Details of the questionnaires used in this study can be obtained from the author.

Material published as part of these proceedings, either on-line or in print, is copyrighted by Informing Science. Permission to make digital or paper copy of part or all of these works for personal or classroom use is granted without fee provided that the copies are not made or distributed for profit or commercial advantage AND that copies 1) bear this notice in full and 2) give the full citation on the first page. It is permissible to abstract these works so long as credit is given. To copy in all other cases or to republish or to post on a server or to redistribute to lists requires specific permission from the publisher at Publister@intommingscience.org

\section{The Skills Gap}

Confirmation of the skills gap can be found in several studies and articles (Farwell, Lee and Trauth 1993, Leonard, 1999). Skilled developers are in short supply and growth in the systems develop- 
The Skills Gap

ment industry is hampered by the lack of competent people (Sargeant, 1998).

Two primary causes have been identified for the skills gap, namely:

- Discordance between industry and academic universities and lack of consensus concerning industry skill requirements (Milton, 2000).

- The dynamic nature of the IT industry creates a set of circumstances that make it extremely difficult to obtain this level of experience before the technology becomes outdated.

A far reaching consequence of the IT skills gap is that companies are forced to increase and improve their own training programmes in order to maintain a certain level of quality (Nuthall, 2001). Re-training of employees is a very expensive solution. It is therefore vital that IT students obtain experience and knowledge within their courses in order to be equipped with sufficient real world skills (Woolf, 2001, Carroll, 1998; Lightfoot 1999). Increasing the collaboration between the industry and academic institutions in order to ensure the convergence of their objectives, would be another way of bridging the skills gap (Farwell, Lee \& Trauth, 1993).

For systems to conform to the needs of the organisation and the users, developers need to be knowledgeable in both business and technical aspects of system development (Farwell, Lee and Trauth, 1995). In addition to this, several surveys and studies also indicated the importance of interpersonal /soft skills in the industry (Cardarella, 1999).

To best equip students for the dramatic technology changes in the IS/IT field, a standardised IS course curriculum becomes a necessity. Several attempts in this regard have been made (Horton and Leitheiser, 1994). The IS '97 Model Curriculum was established to ensure that academic programs would be consistent both with employment needs and with the common body of knowledge of the IS field (AITP (Association of Information Technology Professionals), 1997). The time spent to change curricula to align with changes in the IT industry, remains a problem (Gambill \& Maier, 1996; Lightfoot 1999). It is difficult to find resources necessary for staying technologically up to date as well as to correctly forecast what required skills system developers would need in coming years (Ives, 1993).

\section{The IT Skills Gap with Regards to UCT and South African Industry Requirements}

\section{The Objectives of the Study}

The question that arises from these observations is whether the systems development skills being produced by UCT are aligned with those required by industry. This question presented an opportunity to investigate the quality and adequacy of skills possessed by UCT graduates. It could also provide insight on how to improve the systems development course curriculum at UCT.

In an attempt to answer the above question, three objectives were specified:

1. to measure the degree of alignment between the level of skills possessed by the IS students of UCT and the level of skills demanded by South African systems development companies. A list of seven skills utilised during the study of both IS students and systems development companies was categorised into three skill classifications, based on information brought to light in the literature survey (see Figure 1). The result was useful to determine on what particular skill too much or too little emphasis had been placed within the IS curriculum of UCT.

2. to discover whether IS students of UCT, are skilled in the same technologies that companies regard as most important. The result was intended to identify the skills that industry sees as important, and to indicate the proportion of students skilled in these areas. 
3. to determine whether the IS students obtained the skills that companies view as most important through their formal education at UCT. The result was intended to discover what proportion of students who indicated that they were skilled in an area, also felt that they had obtained this skill through a formal UCT course or any other means directly related to UCT.

\section{Some Limitations of the Study}

The IS curriculum at UCT has changed in the last few years. Some fourth year students may have been involved in courses different from those offered under the current curriculum. As a result, the skills that they have been taught may differ from the skills that students graduating from the university in the next few years may acquire. In an attempt to alleviate this limitation to a certain extent, the responses of both the third year students and the fourth year students have been combined. It could also be that a number of the skills that may be lacking (based on the responses of third year and fourth year students), have already been taken into account in current first and second year IS courses.

Various measures were adopted to promote responses from the systems development companies. Some of these steps included contacting potential respondents and asking them to participate, sending a reminder to non-respondents, assuring respondents of confidentiality and making the survey short and easy to complete.

\section{The Role Players}

Any company that performs systems development within South Africa was considered part of the population or "universe". In order to obtain an unbiased list of all these companies, the South African IT directory of the Cape Information Technology Initiative (CITI) was used as a sampling frame. CITI is a nonprofitable organisation that maintains a comprehensive listing of over 400 IT companies in South Africa. Many of these companies are involved in various aspects of systems development, and the list encompasses a diverse range of companies in terms of size and industry focus.

All third and fourth year IS students eligible for graduation or admission to honours (fourth year) at the end of the 2001, were included in the survey population. A requirement for both courses is a systems development group project. A vital component of the group project is to expose students to real life systems and thus obtain invaluable industry related experience. All groups find their own individual sponsors in industry. The focus for fourth year students would be a generic system, whereas third year students would find sponsors with a business problem to best suit the specifications of the proposed system. The group project is the flagship of the third year course and a major event in the fourth year course. The groups are extremely motivated and intense competition exists amongst them to perform at top level. As a result, it presents the students with the opportunity to acquire a vast number of new skills to enable them to complete the project.

\section{The Survey}

Although the information obtained from industry and the students was essentially the same, it was important that separate research instruments were designed to cater for different requirements. The basic requirements for the industry questionnaire were: easy distribution, quick completion, a clear purpose and easy submission / return. A web-based survey method was used to achieve this. In the students' case the requirements were: the assurance of anonymity, avoidance of bias in terms of the authors' experience and easy completion.

The student questionnaires consisted of a group section and an individual section. A paper-based group section was distributed to both third and fourth year groups to obtain specific information regarding their system development project as a whole. In the individual section students indicated which skills they felt 
The Skills Gap

they possessed at a level adequate to be used within a professional situation. This set of skills included the extra skills that industry added. Students also indicated where they had learnt each skill, either through a UCT course, or via another method. As a result areas outside of the UCT curriculum where students might have learnt skills, were taken into account. Students were also asked to indicate if they used the skill in their systems development project.

All third year students completed both sections of the student questionnaire, which was handed in with the project. The fourth year students and system development companies completed an on-line questionnaire. A $10 \%$ response rate was obtained with regard to system development companies, 424 emails were distributed to companies and 39 responses were recorded. The responses were diverse in terms of the size and nature of the companies that completed the questionnaire. The size of the companies ranged from 1 employee to 3500 employees, and the companies were involved in systems development in a number of diverse industries, including financial, educational and telecommunications.

Approximately 200 questionnaires were distributed to the third year students. 151 students completed the questionnaire. This was a $75.5 \%$ response rate.

The honours class, comprising of 74 students, were all emailed with a request to complete the question-

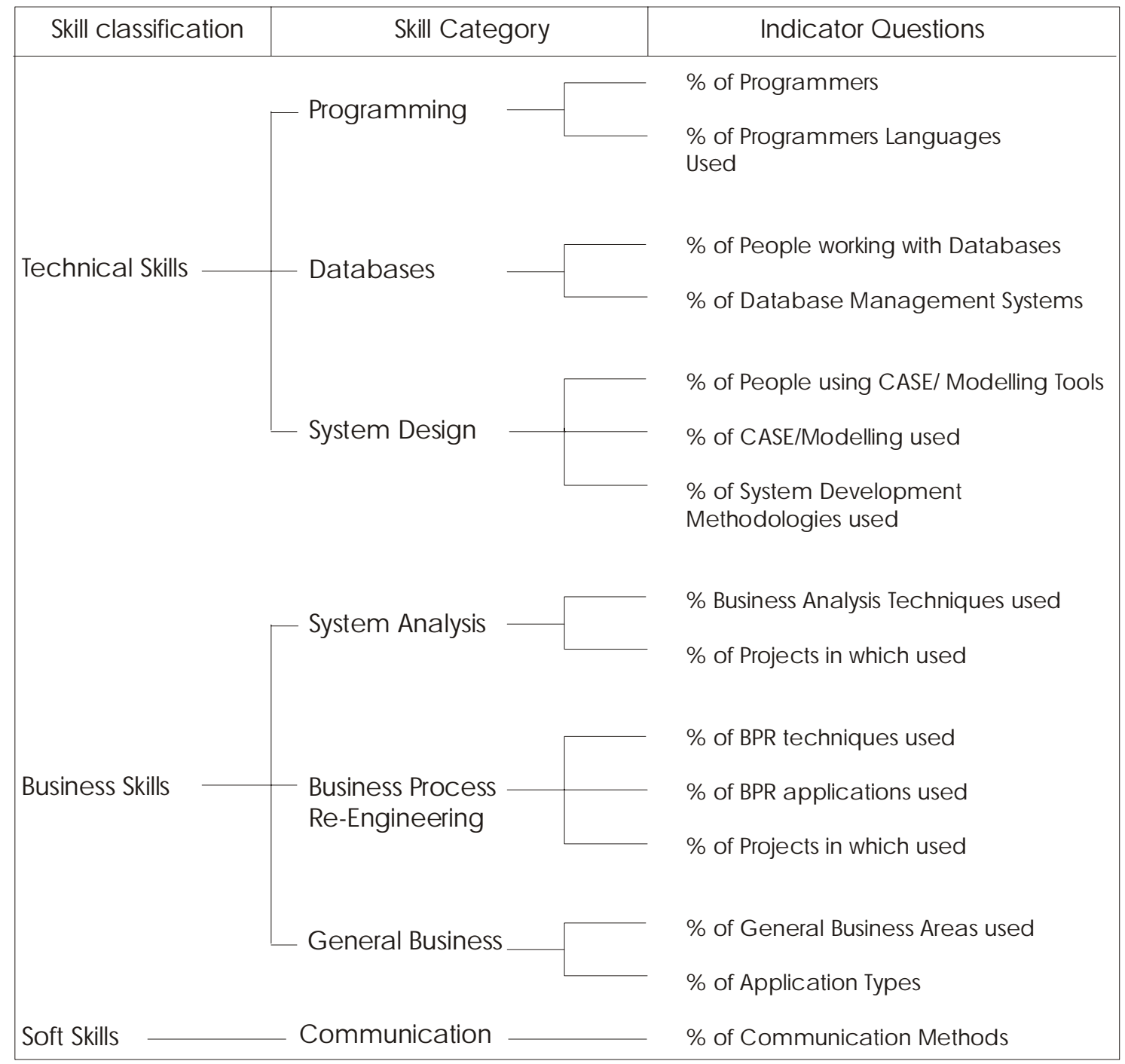

Figure 1: Skill Indicators 
naire. 44 students completed the questionnaire, which is a $60 \%$ response rate. In order to identify the skills of IS students at a graduate level, the third and fourth year students' results were combined.

\section{The Skill Classification}

Two sets of variables played a major role in this study:

- the system development skills that companies require

- the system development skills that IS students of UCT possess.

In an attempt to investigate these variables, the skills were categorised into three skill classifications, where each skill class was divided into different skill categories. For each one of the seven skill categories thus obtained, indicator questions were devised. The diagram in Figure 1 shows the classifications and the indicators for each of the skill areas.

The results of these questions provided an indication of how important companies believed skills in each of the seven skills areas in the skill classification, were.

- From the "percentage of people indicator questions" the percentage of systems developers that perform each skill in a particular company, was obtained.

- The "percentage of skill indicator questions" assisted to determine what percentage of the final skills in each category, a particular company used.

- In some cases it was necessary to measure how often a skill is used. In questions where a respondent selected a range to indicate "how often", a median value was assigned. For example, the value 10 was assigned to the range $0-20 \%, 30$ to the range $21-40 \%$, etc. to provide "a frequency indicator".

Once the above amounts were calculated for each company, an average was obtained for all companies to provide a mean for that particular indicator. The average across each set of indicators questions for each skill category was then calculated and provided an objective figure of how important each company rated each skill category.

Similar indicator questions were used and calculations made to determine how skilled students were in

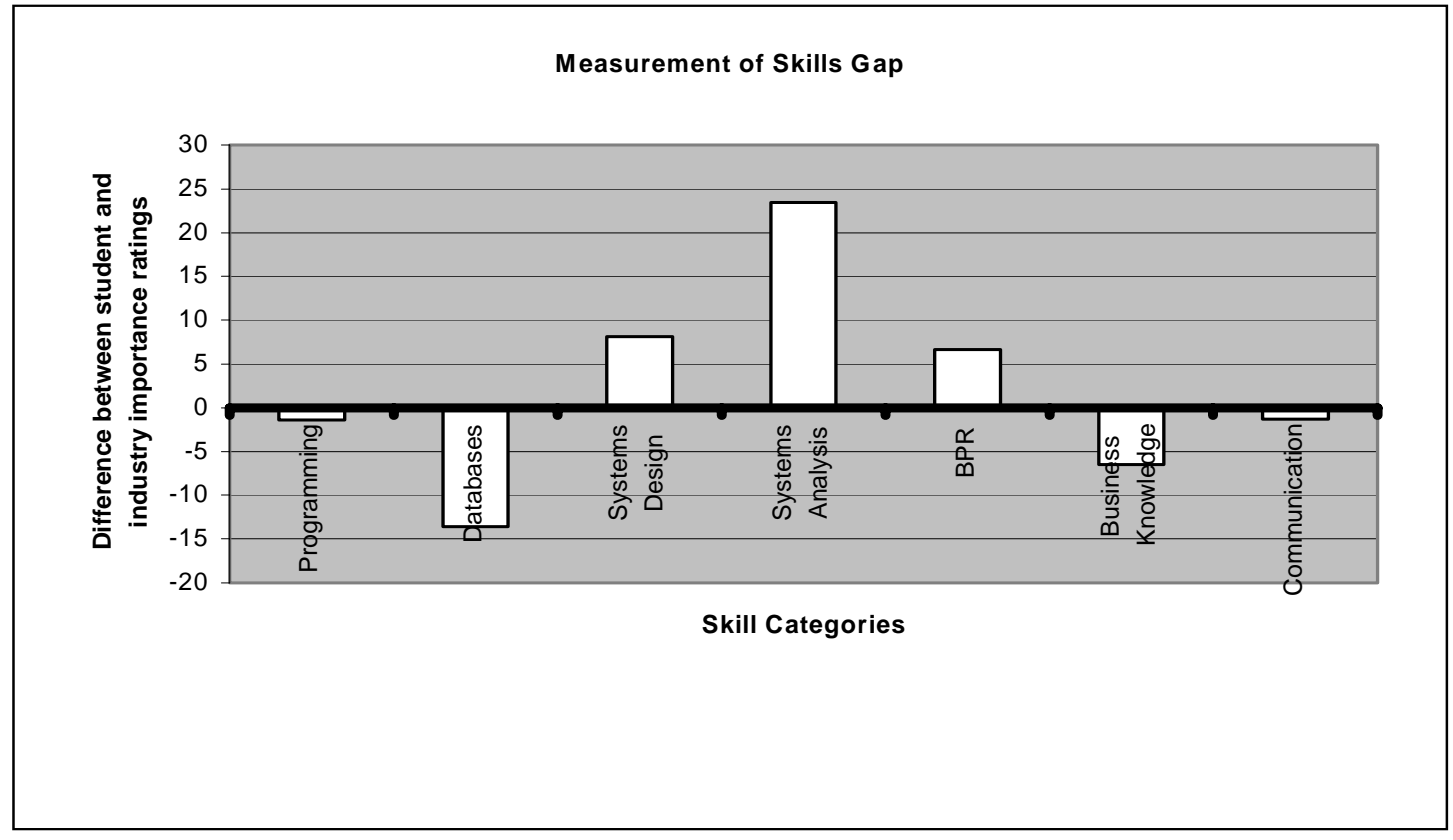

Figure 2: Measurement of Skills Gap 
The Skills Gap

different areas. The difference between the average importance rating for students and that of industry provided valuable information about the alignment of skills between industry and the students.

\section{The Degree of Alignment}

Figure 2 shows the difference between the average importance rating of the companies and the skill rating of the students for each skill category. This difference is a reflection of the alignment between the requirements of the systems development industry and the skills of the IS students at UCT in the specified skills categories. The zero line indicates that there is no difference between the two ratings. The bars above the line indicate that students have a higher skill rating than the importance rating of the companies, whilst the bars below the line indicate that the companies' importance rating is higher than the students' skill rating.

There are significant discrepancies between some of the areas that system development companies believe are most important and those in which IS students are skilled. The largest gap exists in the area of databases and system analysis. The skills gap in the area of programming and communications is particularly small and hence there is a close alignment between the importance rating of companies and the skill rating of students. With regard to the systems design, systems analysis and business process re-engineering areas it appears that students are more skilled than required by the industry importance rating. The database skills gap can be largely attributed to the fact that students tend to be skilled in one or two technologies and not in a complete range as required by industry.

\section{Correlation of Skills}

Not only is it important to examine the importance of skills groupings, but also to identify and compare the top skills and technologies that industry views as important and those that students are skilled in.

Each of the individual skills listed in each skill category was analysed according to the number of companies who indicated that they used the skill, technology or knowledge in their companies. This value was converted into a percentage of the total skills listed. All the skills could then be ranked to determine which skills were mostly required by the systems development industry. Each of the individual skills was examined to determine how many students believed that they were skilled in that area. This number was then converted to indicate a percentage of all the students. The list of skills for each category could then be ranked to ascertain in which skill areas students were most skilled.

Table 1shows a significant correlation between the specific skills required by industry and the number of students that has this specific skill for all the skill categories except for CASE (Computer Aided Software Engineering) /Modelling Tools and BPR (Business Process Re-engineering ) Techniques. This indicates that many of technologies used by the largest proportion of companies are identical to the areas that the greatest number of students are skilled in.

\begin{tabular}{|l|c|c|c|c|}
\hline \multicolumn{1}{|c|}{ Skill Group } & $\mathbf{n}$ & $\mathbf{r}_{\mathbf{s}}$ & $\mathbf{W}_{\mathbf{p}}$ & Correlation \\
\hline Programming Languages & 22 & 0.900339 & 0.4241 & Yes \\
\hline Database Management System & 13 & 0.781593 & 0.5549 & Yes \\
\hline CASE/Modelling Tools & 12 & 0.395105 & 0.5804 & No \\
\hline System Development Methodologies & 14 & 0.853846 & 0.5341 & Yes \\
\hline Business Analysis Techniques & 7 & 0.928571 & 0.745 & Yes \\
\hline BPR Techniques & 6 & 0.114286 & 0.8286 & No \\
\hline General Business Knowledge & 13 & 0.747253 & 0.5549 & Yes \\
\hline Communication Skills & 9 & 0.8875 & 0.6833 & Yes \\
\hline
\end{tabular}


The low correlation in the CASE/ Modelling Tools and Business Process Re-engineering Techniques skill groups could be due to the fact that students tended to be skilled in only one CASE/ Modelling tool (Visio) and the majority of the students indicated that they were skilled in the 'Matrix of Change' whilst this business process re-engineering technique was only used by $3.33 \%$ of companies.

\section{IS Program at UCT}

Each of the top three skills that industry regards as important has been examined with respect to whether students have obtained these skills directly through UCT.

In a number of the skill areas it has emerged that students have obtained one of the specific skills through UCT, whilst the other skills have generally been gained through alternative sources. This is relevant to the programming, databases, modelling and systems development skill categories where it appears as if UCT has structured their curriculum to focus on one specific technology as opposed to teaching a range of skills.

UCT also does not seem to adjust their curriculum to take into account changing technology trends. For example, they concentrate on teaching the systems development lifecycle whilst companies tend to prefer an object-oriented approach.

In the skill areas of business analysis techniques, business process re-engineering techniques and general business knowledge students tended to have acquired the majority of their knowledge from formal UCT courses.

It appears that students are acquiring a significant proportion of their knowledge through formal UCT courses and that areas that are lacking are mainly the range of technologies taught, and not the theory.

\section{Conclusions}

Based on the findings of this study, the following conclusions may be drawn:

1. There are significant differences between the skills importance rating of companies and students' skill ratings. Except for the areas of programming and communication there are significant differences between the skill categories that system development companies stated as important and the skills possessed by IS students at UCT. This lack of alignment can be attributed to the fact that companies require students to be skilled in a range of technologies as opposed to being skilled in a particular technology. It is vital that IS teaching departments identify the range of skills required by system development companies and focus their curriculum towards offering these skills to students.

2. There is a significant difference between the database skills possessed by Information System students and the requirements of industry. System development companies require a range of database skills. UCT should conduct an investigation into the database management skills required by systems development companies and concentrate their effort on providing these skills to students.

3. There is correlation between the individual skills being taught at the UCT and those required by industry. However, in the instance of CASE/ Modelling Tools and BPR-Techniques, there appears to be no significant correlation. Students are lacking skills in XML, iterative development and business process re-engineering applications. The industry survey revealed that the top applications developed by companies are web-based e-commerce systems (63\% of companies), transaction-processing systems (57\% of companies) and Customer Relationship Management systems (50\%). For web-based applications students need to be skilled in, for example, XML. These facts should be taken into account when designing systems development projects. 


\section{The Skills Gap}

4. The system development skills of students can be directly related to UCT's IS curriculum. From the data it appears that with regard to theoretical skills, UCT provides the necessary theoretical skills. In terms of technical skills, the university tends to concentrate on one specific technology and does not teach a range of skills in formal courses.

\section{Recommended Further Research}

The findings of this study are ideal for use in curriculum design for an entire systems development program. Not only should the content and skills being taught in the courses be aligned with what industry requires, but it is also important that the quality level of these skills is of a satisfactory level. Where specific skills are currently being taught, research should be conducted into the quality level of those skills once the students have completed the course.

The focus of this research has been directed at the IS department of UCT alone. Comparative studies could be conducted at other universities on a national or an international basis. This could lead to valuable insights into course design and the implementation of systems development projects.

\section{References}

AITP (1997) 'IS'97 - Model Curriculum and Guidelines for Undergraduate Degree Programs in Information Systems.' . Association of Information Technology Professionals. Accessed: 2001, April 25, 2001 at http://www.IS-97.org/abstract.htm.

Alger, R., Pequeno, S. \& Sessions, N. (2001) 'An investigation into the skills Gap in the Systems Development Industry. ' An Empirical Research Project in partial fulfilment of the requirements for the B.Com.(Hons) degree in Information Systems at the University of Cape Town.

Cardarella, T. (1999) 'IT professional means more than just programmer' Software Careers. Accessed: 2001, September 23 at http://www.developercareers.com/ddj/articles/1999/9913/9913b/9913b.htm.

Carroll, C. (1998) 'World Group Software aims to become global player' ComputingSA, IT Careers Section [Electronic], 03 August. Accessed April 21, 2001 at http://www.computingsa.co.za/compsaarchive/1998/08/03/careers/car02.htm.

Farwell, D., Lee, D. \& Trauth, E. (1993) 'The IS Expectation Gap: Industry Expectations versus Academic Preparation.' MIS Quarterly, September, vol. 17. issue 3, p. 293.

Farwell, D., Lee, D. \& Trauth, E. (1995) 'Critical Skills and Knowledge Requirements of IS Professionals: A Joint Academic/Industry Investigation.’ MIS Quarterly, September, pp. 313-337.

Gambill, S. \& Maier, J. (1996) 'CIS/MIS curriculum's in AACSB-accredited colleges of business.' Journal of Education for Business [Electronic], July/August, vol. 71, issue 6, p. 329.

Horton, R. \& Leitheiser, R. (1994) 'A Needs Analysis for an IS Masters Program: Comparing Employer and Student Perception.' Journal of Education for MIS, vol. 2, no. 1. International Academy for Information Management.

Ives, B. (1993) 'Educating Tomorrow's Business Leaders About Information and Information Technology', MIS Quarterly, December, vol. 17, no. 4, pp. 27-34.

Junglas, I., Sousa, R. \& Watson, H. (2000) 'Business School Deans Assess the Current State of the IS Academic Field.' Communications of the Associations for Information Systems, vol. 4, article 4, pp. 2 - 27.

Leonard, L. (1999) 'Survey Shows Skills Gap Still a Problem.' [Online]. Information Technology Association of Canada. Accessed: 2001, April 20, 2001 at http://www.itac.ca/.

Lightfoot, J. (1999) 'Fad versus Fundamentals: The Dilemma for Information Systems Curriculum Design.' Journal of Education for Business, September/October, vol. 73, issue 1, p. 43.

Milton, T. (2000) 'Cross training the answer to e-commerce staff shortages.' Computer Weekly [Electronic], 17 Febuary. Reed Elsevier Business Publishing, Ltd. Accessed April 24, 2001 at http://www.cw360.com/.

Nuthall, K. (2001) 'Skills Gap to Slow Europe's E-rise.' Computer Weekly. [Electronic], 11 January. Reed Elsevier Business Publishing, Ltd. Accessed 2001, April 24, 2001 at http://www.cw360.com/. 
Sargeant, T. (1998) 'The Systems Developer - Is There a Future?' ITWeb Limited [Online], 1 September. Accessed April 21, 2001 at http://www.itweb.co.za/sections/techforum/ 1998/9809011256.asp.

Van den Honert, R. (1999) Intermediate Statistical Methods for Business and Economics (2 ${ }^{\text {nd }}$ edition). University of Cape Town Press, Cape Town.

Woolf, R. (2001) ‘A career in IT?' ComputingSA, IT Careers Section [Electronic], 19 March. Accessed April 21, 2001 at http://wWw.computingsa.co.za/compsaarchive/2001/03/19/careers/car01.htm.

\section{Biography}

Elsje Scott is a Senior Lecturer in the Department of Information Systems at the University of Cape Town. She teaches a programming course for first year students and is the course convenor and lecturer for the third year System Development Group Project course. She is currently busy with a joint research project "Tracking Student Project States" from Weekly Reports and deliverables.

Rob Alger is at present working as a systems analyst and architect at Candor Technologies in Cape Town. This company was listed amongst the SA TOP 50 ICT companies for 2001/2002. He graduated from the University of Cape Town with an Honours degree in Information Systems in 2001.

Simon Pequeno is at present working at a Cape Town based Information Technology company in the area of system development. He graduated from the University of Cape Town with an Honours degree in Information Systems. His time at UCT has equipped him with the necessary skills to succeed in this industry in 2001.

Nicky Sessions is at present working in the Business Consulting division at Andersen in Johannesburg, South Africa. She is doing a variety of work including general analysis and Peoplesoft implementations. Nicky graduated from the University of Cape Town with an Honours degree in Information Systems. 